\title{
Obtención de inmunoglobulinas de yema de huevo contra Helicobacter pylori producidos en gallinas araucanas ${ }^{\#}$
}

\author{
Obtainment of egg yolk immunoglobulin against Helicobacter pylori produced in araucana hens
}

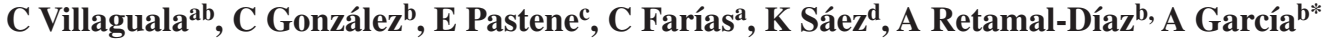 \\ aFacultad de Ciencias Veterinarias, Universidad de Concepción, Chillán, Chile. \\ ${ }^{b}$ Facultad de Ciencias Biológicas, Universidad de Concepción, Concepción, Chile. \\ ${ }^{\mathrm{c}}$ Facultad de Química y Farmacia, Universidad de Concepción, Concepción, Chile. \\ ${ }^{\mathrm{d}}$ Facultad de Ciencias Físicas y Matemáticas, Universidad de Concepción, Concepción, Chile.
}

\begin{abstract}
SUMMARY
Helicobacter pylori is responsible for causing various gastroduodenal diseases, with a worldwide prevalence of 50\% and a prevalence in Chile of 73-76\%. It is necessary to search for more efficient treatment methods for its eradication. In this study, araucana hens were inoculated intramuscularly with H. pylori whole lysates from different H. pylori virulence genotype: strain ATCC 43504 (cagA+, vacAs1ml, dupA-), and strain J99 (ATCC 70824) $(\operatorname{cagA}+, \operatorname{vacAs} 1 \mathrm{ml}, \operatorname{dupA+})$, associated with the development of gastric cancer and duodenal ulcer, respectively. Egg yolk immunoglobulins (IgY) were isolated, mainly through ultrafiltration and ammonium sulfate precipitation at 40\%. IgY against $\mathrm{H}$. pylori, strains J99 and 43504, were purified by thiophilic adsorption chromatography (TAC), obtaining the fractions eluted-peak II and eluted-peak III. The protein concentration for these immunoglobulins ranges between 0.3 and $5.4 \mathrm{mg} / \mathrm{mL}$. The results of polyacrylamide gel electrophoresis (SDS-PAGE) and Western blot (WB) allowed to observe a band of $67 \mathrm{kDa}$ (IgY heavy chain) of immunoglobulins in both strains. By means of indirect immunosorbent assay (I-ELISA), IgY titers against $H$. pylori strains J99 and 43504 were greater than 1/6,400. In cross-reactivity tests among antibodies from several bacteria, there were significant differences. In the prophylactic and therapeutic in vitro assays using a gastric adenocarcinoma cell line (AGS), the fraction of the eluted-peak III of IgY challenged with $H$. pylori demonstrated a high protective efficiency against both strains of $H$. pylori.
\end{abstract}

Key words: Helicobacter pylori, IgY, egg yolk immunoglobulin, araucana hen.

\section{RESUMEN}

Helicobacter pylori es el agente causal de diversas patologías gastroduodenales, con una prevalencia a nivel mundial de 50\% y en Chile de 73-76\%, haciendo necesario tratamientos más eficientes para su erradicación. Este estudio contempló la inoculación intramuscular de gallinas araucanas con lisados completos de dos cepas de H. pylori con diferente genotipo de virulencia: cepa ATCC 43504 (cagA+, vacAs $1 m 1$, dupA-) y cepa J99 (ATCC 70824) (cagA+, vacAs1ml, dupA+), respectivamente asociadas a desarrollo de cáncer gástrico y úlcera duodenal. Se realizó el aislamiento de IgY desde la yema de los huevos recolectados, basado principalmente en ultrafiltración y precipitación con sulfato de amonio al $40 \%$. Mediante cromatografía de adsorción tiofílica (TAC) se purificaron las IgY anti-H. pylori de las cepas J99 y 43504, obteniendo así las fracciones eluida-pico II y eluida-pico III. El rango de concentración proteica de estas inmunoglobulinas fue de 0,3 a $5,4 \mathrm{mg} / \mathrm{mL}$. Mediante electroforesis en geles de poliacrilamida en ambiente reductor (SDS-PAGE) y western blot (WB) se observó una banda de $67 \mathrm{KDa}$ (cadena pesada de IgY) de las inmunoglobulinas de ambas cepas. El título de anticuerpos, mediante ELISA indirecto (ELISA-I), para IgY anti-H. pylori de las cepas J99 y 43504 fue mayor a 1/6.400. En la prueba de reacción cruzada entre los anticuerpos aviares con diversas bacterias hubo diferencias significativas. En los ensayos profilácticos y terapéuticos in vitro utilizando una línea celular de adenocarcinoma gástrico (AGS), la fracción eluida-pico III de IgY desafiada con H. pylori demostró una alta eficiencia protectora contra ambas cepas de H. pylori.

Palabras clave: Helicobacter pylori, inmunoglobulina de yema de huevo, IgY, gallina araucana.

\section{INTRODUCCIÓN}

Helicobacter pylori es un bacilo Gram negativo, microaerófilo, de forma espiralada, colonizador persistente de la mucosa gástrica en humanos (Marshall y Warren 1984,

Aceptado: 18.12.2014.

\# Fuente financiamiento: INNOVA Biobío (Cod. 10 CH S2- 688 F11).

* Casilla 160-C, Concepción, Chile; apgarcia@udec.cl
Ledesma y col 2010), siendo el agente causal de diversas patologías gastroduodenales, desde una gastritis crónica no atrófica hasta un carcinoma gástrico o linfoma tipo MALT (Suerbaum y Michetti 2002). La infección con este patógeno abarca la población mundial con una prevalencia de $90 \%$ en los países en vías de desarrollo (Rivas-Traverso y Hernández 2000, Logan y Walker 2001) y entre $11 \%$ y 40\% en los países industrializados (Martínez y col 2008). En el caso de Chile, la prevalencia, por análisis serológicos en población adulta asintomática fluctúa entre $73 \%$ y $76 \%$ (Ferreccio y col 2007). 
El éxito que ha tenido H. pylori en infectar y colonizar por décadas a sus hospederos se debe a que este microorganismo cuenta con varios genes que codifican para factores de virulencia importantes, entre ellos se encuentra: vacA (Atherton y col 1995), babA (Björnham y col 2009), oipA (Kudo y col 2004), dupA (Arachchi y col 2007), sabA (Ramírez y Sánchez 2009) y cagA (Covacci y col 1993).

Por tanto, surge la necesidad de contar con un método de diagnóstico y tratamiento para la infección por $H$. pylori que sea sencillo, rápido, de uso masivo y disponible a un menor precio. Para ello se pensó en un método de inmunodiagnóstico utilizando la $\operatorname{IgY}$ obtenida de yema de huevo de gallina inmunizada, por separado, con dos cepas de $H$. pylori, una cuyo genotipo se asocia al desarrollo de úlcera duodenal (cagA+,vacAs $\operatorname{lml} 1, \operatorname{dup} A+)$ y la otra al de cáncer gástrico (cagA+, vacAslml, dupA-).

La razón de la elección de la gallina para la producción de inmunoglobulinas de yema de huevo (IgY) tiene importantes ventajas: obtención de los anticuerpos desde la yema del huevo en vez del suero (Mojca 2003), la productividad de anticuerpos de una gallina ponedora es mucho mayor que la de un mamífero de similar tamaño (Hau y Hendriksen 2005), no presenta reacciones cruzadas con los factores reumatoideos (Larsson y col 1991), no activa el sistema de complemento mamífero (Carlander y Larsson 2001), no interfieren con las heteroaglutininas humanas en la prueba de Coombs, presentan menor fluorescencia inespecífica en preparaciones inmunofluorescentes y suelen reconocer varias regiones del antígeno de superficie, resultando en una señal final más marcada en ensayos inmunológicos (Tini y col 2002).

Considerando lo anteriormente expuesto, en el presente estudio se investigó la producción de $\operatorname{IgY}$ anti-H. pylori contra las cepas J99 y 43504, anticuerpos extraídos de las yemas de huevos de gallinas araucanas (Gallus inauris) (Wilhelm 1953) y se determinó si estos ejercen un efecto protector contra ambas cepas bacterianas de $\mathrm{H}$. pylori en la línea celular de adenocarcinoma gástrico humano (AGS) en ensayos terapéuticos y profilácticos efectuados in vitro. Finalmente, se pudieron determinar y purificar las proteínas inmunodominantes de las IgY anti-H. pylori contra las cepas J99 y 43504, al evaluar su especificidad y sensibilidad.

\section{MATERIALES Y MÉTODOS}

\section{OBTENCIÓN Y CUANTIFICACIÓN PROTEICA DE CEPAS DE}

H. pylori

Las cepas de H. pylori (ATCC 43504 y J99) fueron cultivadas separadamente en placas con agar Columbia (Oxoid) y suplementadas con $5 \%$ (vol/vol) de sangre equina y DENT (Oxoid), a $37{ }^{\circ} \mathrm{C}$, durante 4 días, bajo condiciones de microaerofilia $\left(5 \% \mathrm{O}_{2}, 10 \% \mathrm{CO}_{2}, 85 \%\right.$ $\mathrm{N}_{2}$ ). Se cosecharon ambas cepas de $H$. pylori desde sus placas y se transfirieron dentro de tubos con TFS (tampón fosfato salino) $\mathrm{pH} 7,2$. El material celular fue removido por centrifugación a $8.000 \mathrm{rpm}$ por 10 minutos a $4{ }^{\circ} \mathrm{C}$ y luego fue sonicado en 3 ciclos en baño de hielo (20 segundos cada ciclo, $100 \%$ de amplitud y 60 segundos de descanso entre los ciclos). Las concentraciones de proteínas del lisado completo se determinaron por el método del ácido bicinconínico siguiendo las instrucciones del fabricante (BCA Protein Assay kit, Pierce).

\section{INMUNIZACIÓN DE GALLINAS}

Se inocularon tres grupos de gallinas araucanas (32 semanas de edad; $\mathrm{n}=21$ ) de la siguiente forma: el primer grupo constituido por dos gallinas (control negativo) a las cuales se les inyectó TFS pH 7,2; el segundo grupo constituido por 10 gallinas inmunizadas con lisado completo de H. pylori, cepa J99; y el tercer grupo formado por nueve gallinas inmunizadas con lisado completo de $\mathrm{H}$. pylori cepa ATCC 43504.

Las gallinas fueron inyectadas a ambos lados de la pechuga ( $300 \mu \mathrm{l}$ por sitio) con lisado completo de H. pylori $(50 \mu \mathrm{g} / \mathrm{mL}$, proteínas), usando igual volumen de adyuvante completo de Freund (SIGMA). Dos semanas después, las gallinas recibieron tres inyecciones de refuerzo, con adyuvante incompleto de Freund (SIGMA), con un intervalo de dos semanas entre las inyecciones. Al día posterior al segundo refuerzo se inició la recolección diaria de los huevos durante cuatro semanas, estos se almacenaron inmediatamente después de recolectados a $4{ }^{\circ} \mathrm{C}$.

\section{EXTRACCIÓN DE IGY ANTI-H. pylori DESDE LAS YEMAS DE} LOS HUEVOS DE GALLINA

Se realizó la separación de las yemas de las claras del conjunto de huevos de los tres grupos de gallinas diariamente. Cada conjunto de yemas $\left(4^{\circ} \mathrm{C}\right)$ se diluyó con nueve volúmenes de agua destilada refrigerada $\left(4^{\circ} \mathrm{C}\right)$ y homogeneizó por un minuto usando una juguera (Waring) a alta velocidad. Se ajustó el pH de la solución de yemas a pH 5 con $\mathrm{HCl} 3 \mathrm{~N}$ y centrifugó a $2.800 \mathrm{x}$ g por 40 minutos a $4{ }^{\circ} \mathrm{C}$.

Después de la centrifugación, al sobrenadante recolectado se le agregó 0,05\% de carbón activado, se ajustó a pH 4 con $\mathrm{HCl} 1 \mathrm{~N}$ y nuevamente se centrifugó a 2.800 x g por 30 minutos a $4{ }^{\circ} \mathrm{C}$ para remover las lipoproteínas residuales en el sobrenadante. El sobrenadante se filtró empleando un papel filtro Whatman $\mathrm{N}^{\circ} 1$ y luego se realizó una ultrafiltración utilizando tubos de $15 \mathrm{~mL}$ con filtros de membrana de poro de tamaño de corte de 100 $\mathrm{kD}$ (Amicon Ultracel).

A la solución de la muestra concentrada por ultrafiltración se le realizó una precipitación de las proteínas mediante sulfato de amonio. Para tal efecto se precipitó con sulfato de amonio saturado al $40 \%$ (pH 9) y luego se centrifugó a $4.500 \mathrm{rpm}$ por 20 minutos a $4{ }^{\circ} \mathrm{C}$. Posteriormente el pellet fue precipitado en Tris- $\mathrm{HCl} 0,01 \mathrm{M}(\mathrm{pH} 8)$ a un volumen igual a la mitad del sobrenadante. La muestra nuevamente 
fue precipitada con sulfato de amonio saturado al $40 \%$ y centrifugada a $4.500 \mathrm{rpm}$ por 20 minutos a $4{ }^{\circ} \mathrm{C}$. El pellet fue resuspendido en TFS $1 \mathrm{x}(\mathrm{pH} 7,2)$ y fue dializado 4 veces con TFS $0,5 \mathrm{x}(\mathrm{pH} 7,2)$, durante 48 horas para remover el $\mathrm{NaCl}$.

PURIFICACIÓN DE LA IGY ANTI-H. pylori CEPAS J99 Y 43504 POR CROMATOGRAFÍA DE ADSORCIÓN TIOFÍLICA A PARTIR DE LAS YEMAS PROCESADAS PREVIAMENTE

Las muestras procesadas al final de la etapa anterior (extracción de IgY anti-H. pylori desde las yemas de los huevos de gallina) fueron purificadas por Cromatografía de Adsorción Tiofílica (TAC) por medio de una resina (Clontech) de afinidad para las inmunoglobulinas y $\alpha_{2}$ macroglobulinas. Previo a la purificación de las proteínas se solubilizaron $335 \mathrm{mg}$ de sulfato de sodio anhidro $\left(\mathrm{Na}_{2} \mathrm{SO}_{4}\right)$ en $5 \mathrm{~mL}$ de muestra y se filtró con poros de $0,45 \mu \mathrm{m}$. Luego se ensambló y empaquetó la columna de cromatografía con $10 \mathrm{~mL}$ de la resina resuspendida con agua ultrapura (MiliQ, Millipore Corporation) y se esperó a que esta se estabilizara dentro de la columna. Luego se pasó por la columna el tampón de equilibrio $(50 \mathrm{mM}$ de fosfato de sodio; 0,5 M de sulfato de sodio; $\mathrm{pH} 7,0$ ) a una velocidad de flujo de $4 \mathrm{~m} \mathrm{~L} / \mathrm{min}$, un volumen 10 veces mayor al volumen de la columna. Posteriormente se procedió a pasar por la columna la muestra ( $\operatorname{IgY}$ anti-H. pylori en su forma bruta de la cepa correspondiente) pretratada con sulfato de sodio anhidro, a una velocidad de $2 \mathrm{~mL} / \mathrm{min}$, para así recolectar las proteínas no unidas, las que generaron el pico I en el equipo cromatográfico (Biorad, Econo UV Monitor, Data Q Instrument Hardware Manager). A continuación se pasó por la columna el tampón de elución ( $20 \mathrm{mM}$ de fosfato de sodio, $20 \%$ de glicerol, $\mathrm{pH} 7,0$ ) y el tampón de regeneración (Tampón 1: el mismo tampón de elución; y Tampón 2: $35 \mathrm{mM}$ de fosfato de sodio, $30 \%$ n-propanol, ph 7,0) para la recolección del anticuerpo purificado en sus fracciones eluida-pico II y eluida-pico III. Finalmente se pasó etanol al $25 \%$ por la columna y se conservó a $4{ }^{\circ} \mathrm{C}$ para un futuro uso. Se determinó la concentración proteica de IgY anti-H. pylori cepas J99 y 43504 en su forma no purificada (en bruto) y purificadas (eluida-pico II y eluida-pico III) mediante el método del ácido bicinconínico siguiendo las instrucciones del fabricante (BCA Protein Assay kit, Pierce).

\section{ELISA INDIRECTO}

La presencia de inmunoglobulinas IgY en el extracto de yemas con especificidad para H. pylori cepa J99 y 43504 se determinó por el método inmunoenzimático de ELISA indirecto. Las proteínas totales de H. pylori cepas J99 y 43504 fueron diluidas en tampón carbonato-bicarbonato $(50 \mathrm{mM}$, pH 9,6) en una concentración final $10 \mu \mathrm{g} / \mathrm{mL}$ (previamente determinada por titulación del antígeno). Las diluciones fueron usadas para la inmovilización del antígeno en placas de poliestireno de 96 pocillos (Nunc Immunoplate Maxisorp,
Denmark), por incubación a $4{ }^{\circ} \mathrm{C}$ durante toda la noche en cámara húmeda. Posteriormente se lavaron las placas tres veces con tampón TFS/Tween (TTFS: TFS y $0,05 \%$ de Tween 20) y se les adicionó tampón de bloqueo (TTFS y gelatina al $0,8 \%[\mathrm{w} / \mathrm{v}]$ ) y se incubaron por una hora a $37^{\circ} \mathrm{C}$, en cámara húmeda. Luego, se lavaron tres veces durante un minuto con TTFS y se incubaron durante dos horas a $37^{\circ} \mathrm{C}$, en cámara húmeda, con diferentes diluciones de los extractos de yema enriquecidos en IgY anti- $H$. pylori cepa J99, 43504 y un control negativo (proveniente de gallinas inoculadas con TFS pH 7,2) disueltas en tampón para anticuerpos (TTFS y $0,2 \%$ de gelatina). Al finalizar el periodo de incubación las placas se lavaron tres veces con TTFS. Posteriormente se incubaron con un anticuerpo monoclonal de ratón de clase IgG1 anti-IgY de gallina (Sigma Aldrich), el que se utilizó en una dilución de 1/2.000 en tampón para anticuerpo y se incubó por una hora a $37^{\circ} \mathrm{C}$, en cámara húmeda. Luego se lavaron tres veces durante un minuto con TTFS y se incubaron con un anticuerpo monoclonal de cabra anti-IgG1 de ratón conjugado con peroxidasa (ImmunoResearch) en una dilución de 1/5.000 en tampón para anticuerpos, y se incubó nuevamente por una hora a $37{ }^{\circ} \mathrm{C}$, en cámara húmeda. Finalizada la incubación, las placas fueron lavadas tres veces y reveladas adicionando una solución de ortofenildiamina (OPD/Fast, Sigma-Aldrich, Inc.) a razón de $0,4 \mathrm{mg} / \mathrm{mL}$, incubando por 30 minutos a temperatura ambiente y en oscuridad. Finalmente se realizó la lectura de la reacción colorimétrica empleando un lector de microplacas a una longitud de onda de $450 \mathrm{~nm}$ (Victor3, PerkinElmer).

\section{DETERMINACIÓN DE REACCIONES CRUZADAS CON OTRAS} BACTERIAS

La reactividad cruzada de las inmunoglobulinas IgY en el extracto de yemas con especificidad para $H$. pylori cepa J99 y 43504 se determinó por el método inmunoenzimático de ELISA indirecto ya descrito, para esto se utilizaron proteínas totales de $H$. pylori cepa 43504, $H$. pylori cepa J99, Micrococcus luteus, Streptococcus faecalis, S. enterica subsp. enterica serovar Typhimurium, S. enterica subsp. enterica serovar Enteritidis, Vibrio parahaemolyticus, Shigella sonnei, Pseudomonas aeruginosa, Escherichia coli O157:H7, Citrobacter freundii, Staphylococcus aureus ATCC 6538, Enterobacter cloacae, Yersinia enterocolitica, Shigella flexneri, Campylobacter jejuni, Campylobacter coli, Listeria monocytogenes y Arcobacter butzleri.

\section{SDS-PAGE}

Se preparó un gel completo (por triplicado) dispuesto en diferentes porcentajes de sus componentes: gel concentrador al 5\% (AB-6: 0,6 mL; gel tampón (3x): 1,5 mL; $\mathrm{H}_{2} \mathrm{O}$ destilada: $3 \mathrm{~mL}$; APS: $30 \mu \mathrm{L}$; temed: $10 \mu \mathrm{L})$; gel intermedio al 10\% (AB-6: $1 \mathrm{~mL}$; gel tampón (3x): 1,65 mL; $\mathrm{H}_{2} \mathrm{O}$ destilada: $2,32 \mathrm{~mL}$; urea: $1,8 \mathrm{~g}$; APS: $25 \mu \mathrm{L}$; temed: $8 \mu \mathrm{L}$ ); 
y gel separador al 16\% (AB-6: 3,2 mL; gel tampón (3x): 3,2 mL; $\mathrm{H}_{2} \mathrm{O}$ destilada: 2,5 mL; glicerol: $1 \mathrm{~g}$; urea: 3,6 g; APS: $50 \mu \mathrm{L}$; temed: $16 \mu \mathrm{L}$ ). Los carriles se cargaron con 10 $\mu \mathrm{L}$ de muestra (lisados completos de H. pylori, cepas J99 y 43504 y lisado completo de $E$. coli) y en forma de tripletes, más un carril cargado con un marcador de peso molecular (Precision Plus Protein All Blue Standards, Biorad), homogeneizados con $4 \mu \mathrm{L}$ de tampón de carga. Luego los geles cargados con sus muestras se llevaron a un termobloque (Multi-Blok, Lab Line) a $95{ }^{\circ} \mathrm{C}$ por cinco minutos. El gel se corrió a 50 volts, por 40 minutos y luego a 100 volts por 80 minutos. Uno de los geles se tiñó con azul de coomassie para corroborar la presencia de bandas de proteínas en los carriles y los otros dos geles se utilizaron en western blot.

\section{WESTERN BLOT}

Los dos geles sin teñir, obtenidos de la electroforesis (SDS-PAGE), se sumergieron en metanol por 15 segundos, luego se lavaron dos veces con agua destilada y se sumergieron en tampón de transferencia por cinco minutos. Ambos geles se pusieron en el equipo de transferencia (Biorad, Transblot SD Semi-Dry Transfer Cell) a 10 volts durante tres horas. Se cortaron las membranas en tripletes de proteínas y se dejó cada fracción de la membrana de transferencia sumergida en leche descremada al 5\% incubándolas a $4{ }^{\circ} \mathrm{C}$ durante toda la noche; luego de la incubación de las membranas fueron sumergidas durante cuatro horas en una solución de leche descremada conteniendo el anticuerpo primario (IgY anti-H. pylori de las gallinas preparadas en este trabajo), diluido 1/1000. Los anticuerpos primarios de IgY anti-H. pylori utilizados fueron los siguientes: IgY anti-H. pylori cepas J99 y 43504 en sus formas no purificada (en bruto) y purificadas (eluida-pico II y eluida-pico III). Luego las membranas se lavaron tres veces con TFS-Tween al $0,1 \%$ con agitación por 10 minutos en cada sesión. A continuación las membranas de transferencia se sumergieron con el anticuerpo secundario diluido 1/50. Luego las membranas se lavaron tres veces con TFS-Tween al 0,1\% con agitación por 10 minutos en cada sesión.

Posteriormente se sumergieron las membranas de transferencia con el anticuerpo conjugado con peroxidasa diluido 1/100. Luego las membranas se lavaron tres veces con TFS-Tween al 0,1\% con agitación por 10 minutos en cada sesión.

Finalmente se agregó diaminobencidina $(0,7 \mathrm{mg} / \mathrm{mL}$ de D.A.B.; $10 \mathrm{~mL} \mathrm{H}_{2} \mathrm{O} ; 15 \mu \mathrm{L}$ de peróxido de hidrógeno) a cada fracción de membrana de transferencia y se mantuvieron en agitación por 5 minutos protegiéndolas de la luz. Al finalizar dicho tiempo se observaron bandas teñidas de color café.

DESAFÍO IN VITRO DE IGY CON H. pylori EN CÉLULAS AGS

Para el desafío se empleó la línea celular de AGS (SIGMA). Las células AGS fueron cultivadas en medio
RPMI-1640 (Gibco, Invitrogen Corporation), suplementadas con $10 \%$ (vol/vol) de suero fetal bovino (Biological Industries Kibbutz Beit Haemek Israel) y 1\% (vol/vol) de solución antibiótica de penicilina-streptomicina (SIGMA) a $37^{\circ} \mathrm{C}$ bajo un ambiente de $5 \%$ de $\mathrm{CO}_{2}$ durante dos semanas. Las células AGS fueron chequeadas hasta que alcanzaron una confluencia de $80-90 \%$ de la placa.

Se realizaron dos ensayos, uno profiláctico y uno terapéutico. Entendiéndose como tratamiento profiláctico aquel que implicó la administración de la IgY anti-H. pylori contra las cepas J99 y 43504 previo a la infección de las células AGS. Además, el tratamiento terapéutico implicó el uso de estos anticuerpos posterior a la infección de las células AGS.

En estos ensayos profilácticos y terapéuticos se hizo el desafío de la IgY anti-H. pylori contra las cepas J99 y 43504 en su forma no purificada (en bruto) y purificadas (eluida-pico II y eluida-pico III) preparadas a diferentes concentraciones (al 100\%, 50\% y 25\%).

Para ambos ensayos se utilizaron placas de cultivo celular de 24 pocillos (SPL Life Sciences) y se utilizó un volumen de $350 \mu \mathrm{L}$ del anticuerpo junto con $650 \mu \mathrm{L}$ de RPMI-1640 enriquecido con suero fetal bovino y libre de antibióticos. El inóculo bacteriano usado fue de $100 \mu \mathrm{L}$ de resuspensión de $H$. pylori (concentración de 0,5 en escala de McFarland, equivalente a 1,5 x $10^{8} \mathrm{UFC} / \mathrm{mL}$ ) en medio RPMI-1640 (sin adición de antibióticos) enriquecido con suero fetal bovino. Además, al final del ensayo se adicionó $1 \mathrm{~mL}$ de reactivo urea-rojo fenol a cada pocillo para luego traspasar $250 \mu \mathrm{L}$ de cada pocillo a una placa de cultivo celular de 96 pocillos para medir la absorbancia en un lector de placas a $570 \mathrm{~nm}$ (Biotek). Las condiciones de incubación (tiempo, temperatura y porcentaje de $\mathrm{CO}_{2}$ ) al adicionar el anticuerpo aviar, el inóculo bacteriano y el reactivo urea-rojo fenol fueron de cuatro horas, dos horas y seis horas, a una temperatura de $37^{\circ} \mathrm{C}$, en un ambiente de $5 \%$ de $\mathrm{CO}_{2}$.

\section{ANÁLISIS ESTADÍSTICO}

Se utilizó el software Infostat, versión 2013, con el que se realizó un análisis de varianza (ANOVA) de una y dos vías; cuando resultó significativo este análisis se realizaron contrastes. En este análisis se utilizó un nivel de significancia de 0,05 .

\section{RESULTADOS}

La concentración proteica de IgY anti-H. pylori contra las cepas J99 y 43504 en su forma no purificada (bruta) y purificadas (eluida-pico II y eluida-pico III) fue muy alta para la fracción no purificada pero baja para las fracciones purificadas (figura 1).

Las bandas de mayor inmunogenicidad obtenidas por SDS-PAGE y posterior western blot fueron aquellas que se ubicaron en el rango de los $70 \mathrm{KDa}$, situación que fue 


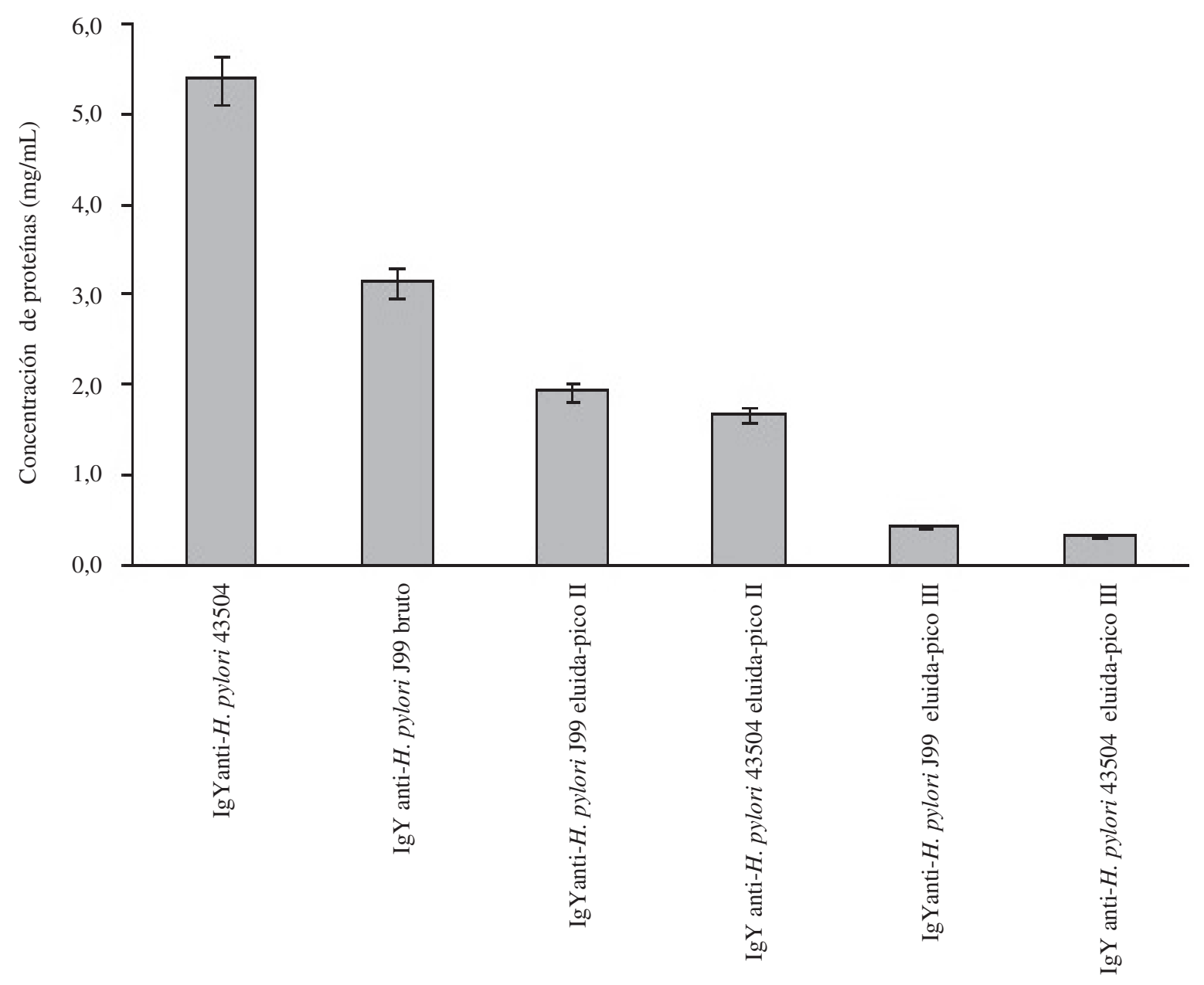

IgY anti-H. pylori

Figura 1. Concentración de proteínas de IgY anti-H. pylori cepas J99 y 43504 en sus formas no purificada (en bruto) y purificadas (eluida-pico II y eluida-pico III). peak III) forms.

Protein concentrations of IgY against H. pylori strains J99 and 43504 in their non-purified (crude) and purified (eluted-peak II and eluted-

común en los lugares donde se formó el complejo antígenoanticuerpo constituido por los antígenos de $H$. pylori con IgY anti-H. pylori, el que además fue reconocido en forma específica por el anticuerpo secundario correspondiente al anticuerpo monoclonal de ratón de clase IgG1 anti-IgY de gallina. Otra banda también reconocida, pero en menor grado, fue la ubicada en el rango de los $22 \mathrm{KDa}$, pero esta solo fue visible en la fracción eluida-pico III mediante SDS-PAGE. Se presentó una gran cantidad de proteínas visibles en el rango de los 12 a $30 \mathrm{KDa}$, visibles mediante SDS-PAGE (figura 2).

Mediante ELISA indirecto, al realizar un análisis comparativo entre los títulos de ambas inmunoglobulinas, se observó que el título de IgY anti-H. pylori contra la cepa J99 frente a los antígenos de su misma cepa y a los antígenos de su cepa heteróloga, en relación con la IgY anti- $H$. pylori contra la cepa 43504 (figuras 3 y 4), fueron muy elevados $(\mathrm{P}<0,0001$ y $\mathrm{P}=0,0001)$ permitiendo su uso en una altísima dilución (alto título de anticuerpos), mayor a 1/6.400, siendo así muy sensible en el reconocimiento de su antígeno.

En la prueba de reacción cruzada se pudo determinar que la IgY anti-H. pylori contra las cepas J99 y 43504 presentaron una alta reacción cruzada contra los antígenos de su misma cepa bacteriana y el de su cepa heteróloga, no habiendo, por tanto, diferencias significativas entre ambos anticuerpos $(\mathrm{P}=0,8579$ y $\mathrm{P}=0,2856)$. A pesar de que $S$. aureus y E. coli presentaron una alta absorbancia en esta prueba, estas bacterias junto con el resto de las otras bacterias testeadas no presentaron reacciones cruzadas respecto de los antígenos de $\mathrm{H}$. pylori, habiendo, por lo tanto, diferencias significativas entre estos antígenos y el resto de antígenos bacterianos $(\mathrm{P}<0,05)$.

En los ensayos profilácticos y terapéuticos realizados in vitro en células de adenocarcinoma gástrico (AGS) se obtuvo una baja absorbancia de la IgY anti-H. pylori 


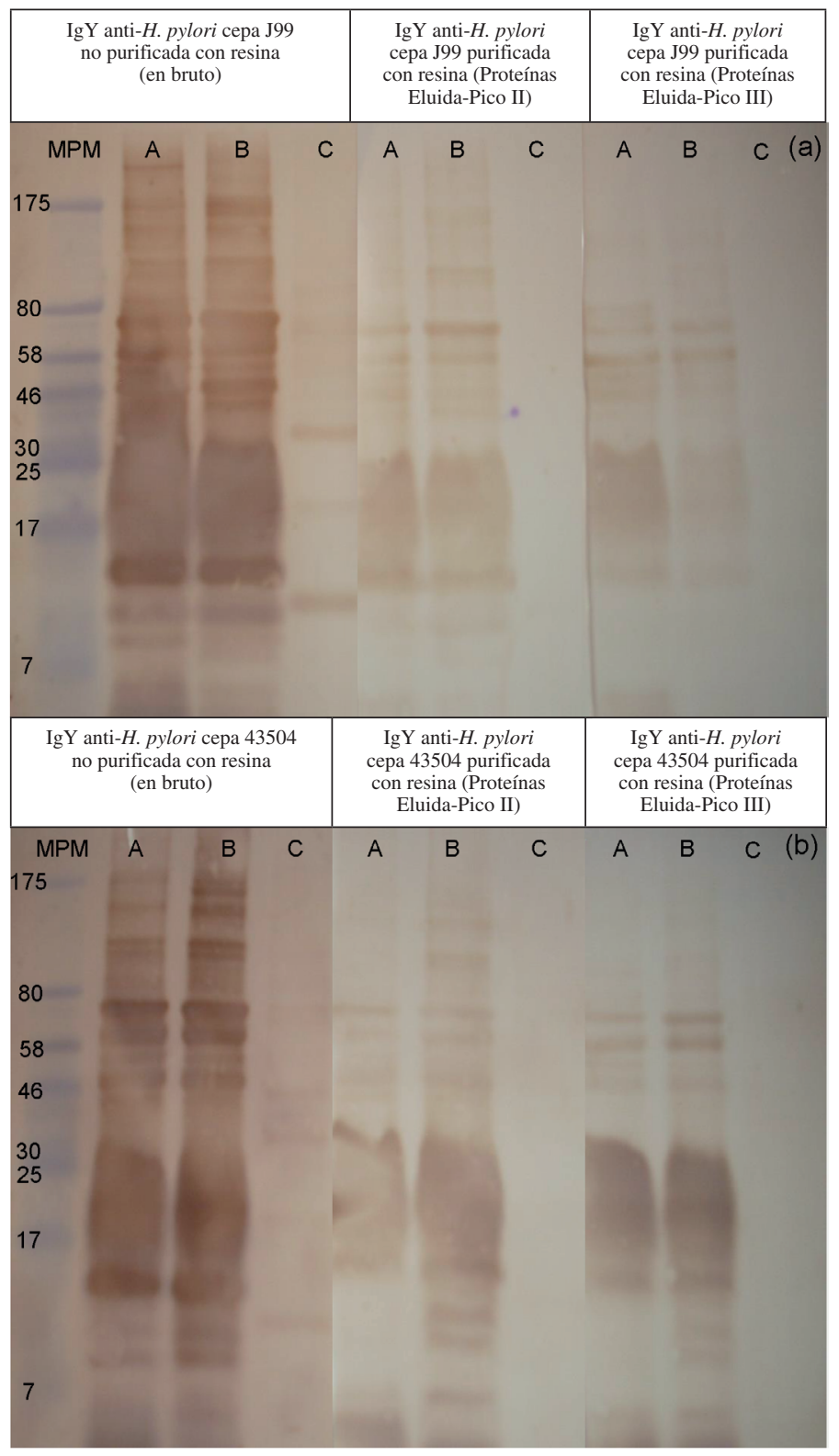

Figura 2. Análisis por western blot del reconocimiento por las fracciones de IgY anti-H. pylori en sus formas no purificadas (en bruto) y purificadas (eluida-pico II y eluida-pico III) obtenidas de la cepa J99 (a) y cepa 43504 (b). Tinción con diaminobencidina. MPM. Marcador de Peso Molecular Biorad; A. Lisado completo de H. pylori cepa J99; B. Lisado completo de H. pylori cepa 43504; C. Lisado completo de E. coli.

Western blot analysis of recognition by fractions of IgY against $\mathrm{H}$. pylori in non-purified (crude) and purified (eluted-peak II and eluted-peak III) forms stained obtained from strains J99 (a) and 43504 (b). Stained with diaminobenzidine. MPM. Molecular Weight Marker Biorad; A. Whole lysate of H. pylori strain J99; B. Whole lysate of H. pylori strain 43504; C. Whole lysate of E. coli.

purificada. En el ensayo profiláctico, al comparar la IgY J99 eluida -pico III al 100\% desafiada con H. pylori cepa J99 (desafío con la menor absorbancia respecto del resto de los otros desafíos) se observó que hubo diferencias significativas en la mayoría de estos ensayos $(\mathrm{P}<0,05)$, excepto en 3 desafíos en los que no hubo diferencias significativas $(P>0,05)$. Sin embargo, en el ensayo terapéutico la cepa bacteriana H. pylori 43504 al ser desafiada con la IgY 43504 eluida-pico III al 100\% (desafío con la menor absorbancia) respecto del resto de los otros desafíos se observaron diferencias significativas en algunos ensayos, pero en la mayoría de ellos (10 desafíos) no hubo diferencias significativas $(\mathrm{P}>0,05)$.

\section{DISCUSIÓN}

De acuerdo con lo publicado por Shin y col (2002) al utilizar el método de $\lambda$-carrageenan y Sunwoo y col (2002) al realizar el método de dilución con agua, pH 5,0, se determinó que la concentración de IgY en la yema de 


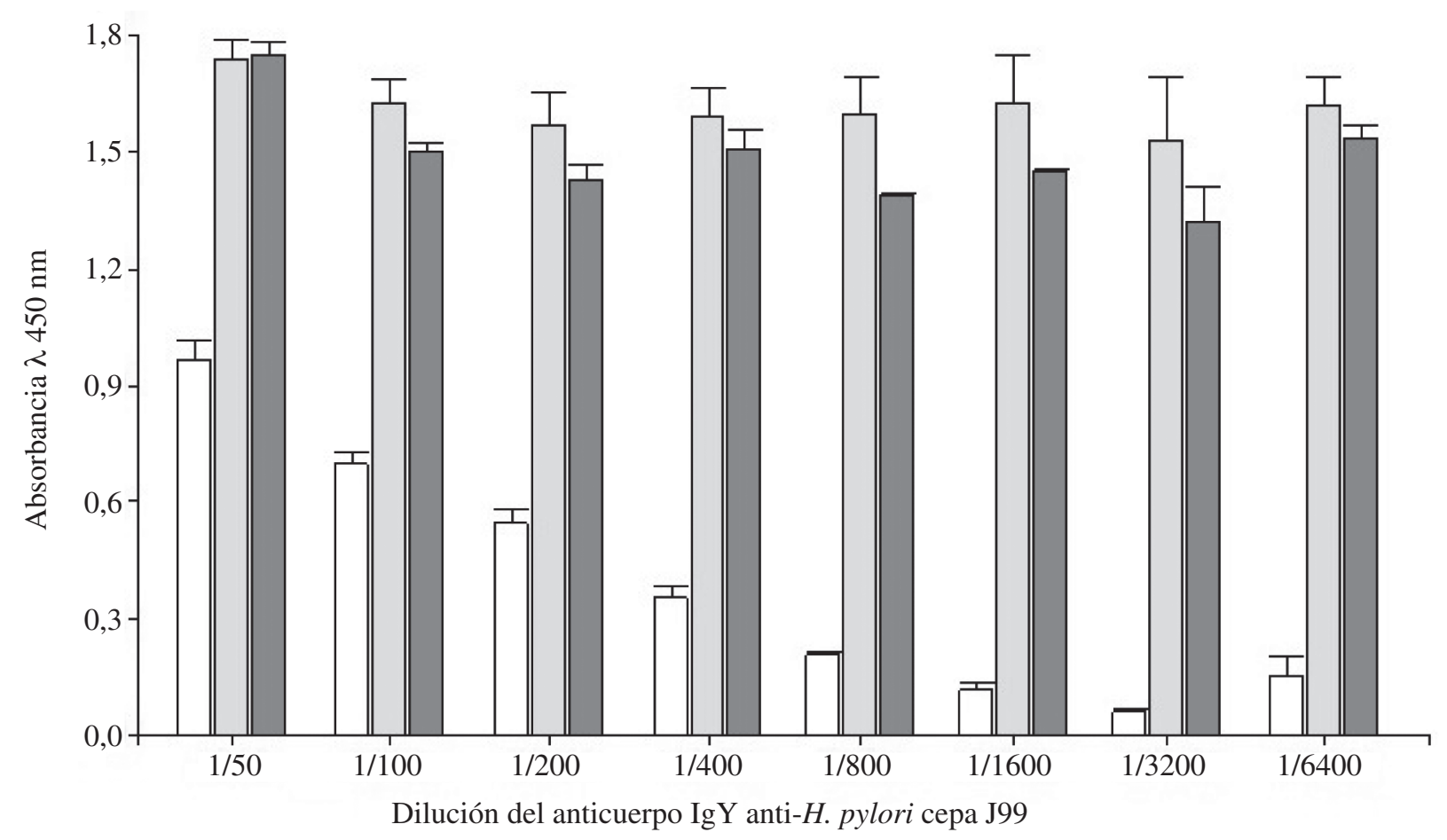

\begin{tabular}{|ll|l|}
\hline Control negativo $\square$ H. pylori J99 $\square$ H. pylori 43504 \\
\hline
\end{tabular}

Figura 3. Titulación del anticuerpo IgY anti-H. pylori cepa J99.

Antibody titer of IgY against $H$. pylori strain J99.

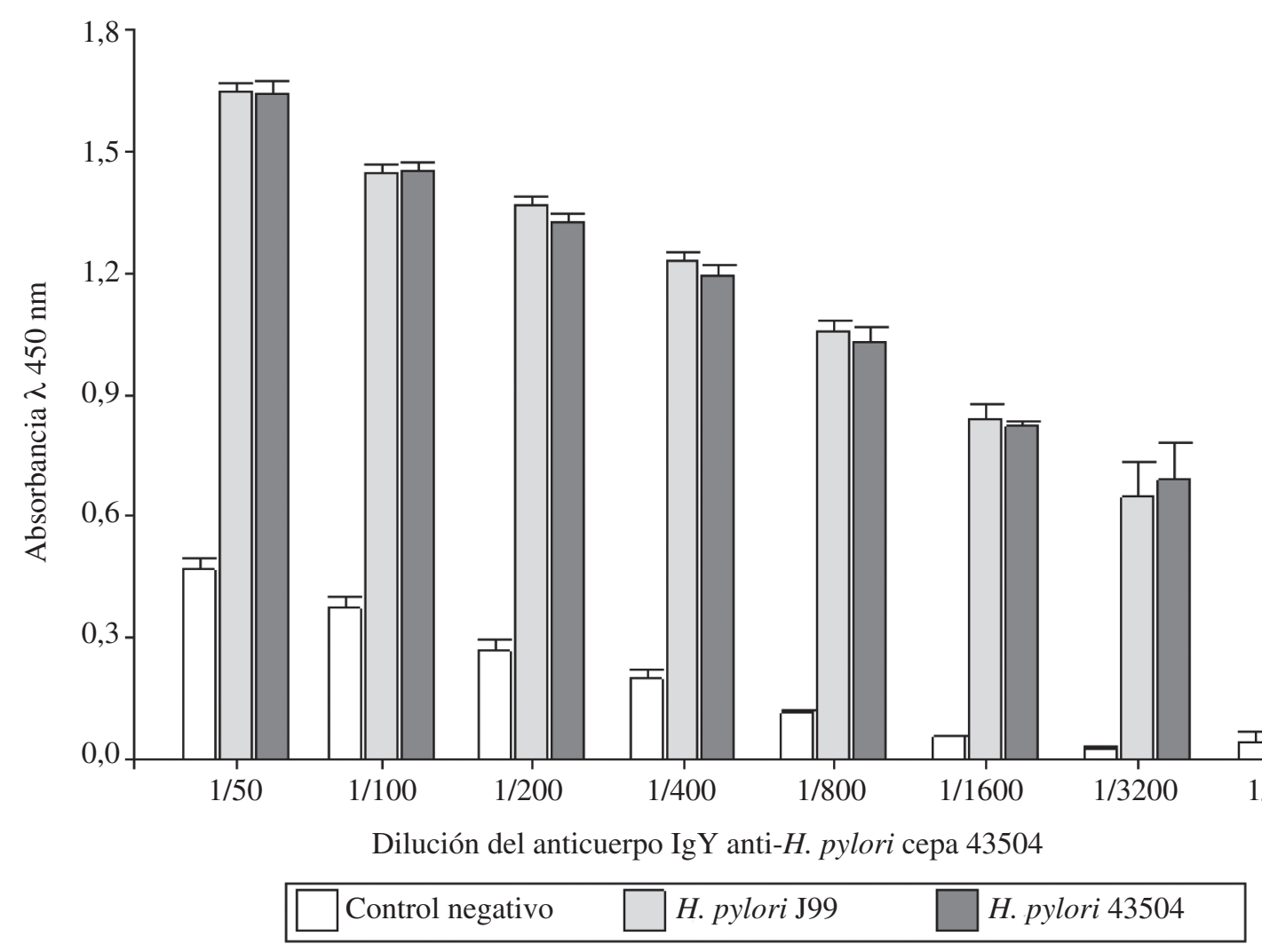

Figura 4. Titulación del anticuerpo IgY anti-H. pylori cepa 43504.

Antibody titer of IgY against H. pylori strain 43504. 


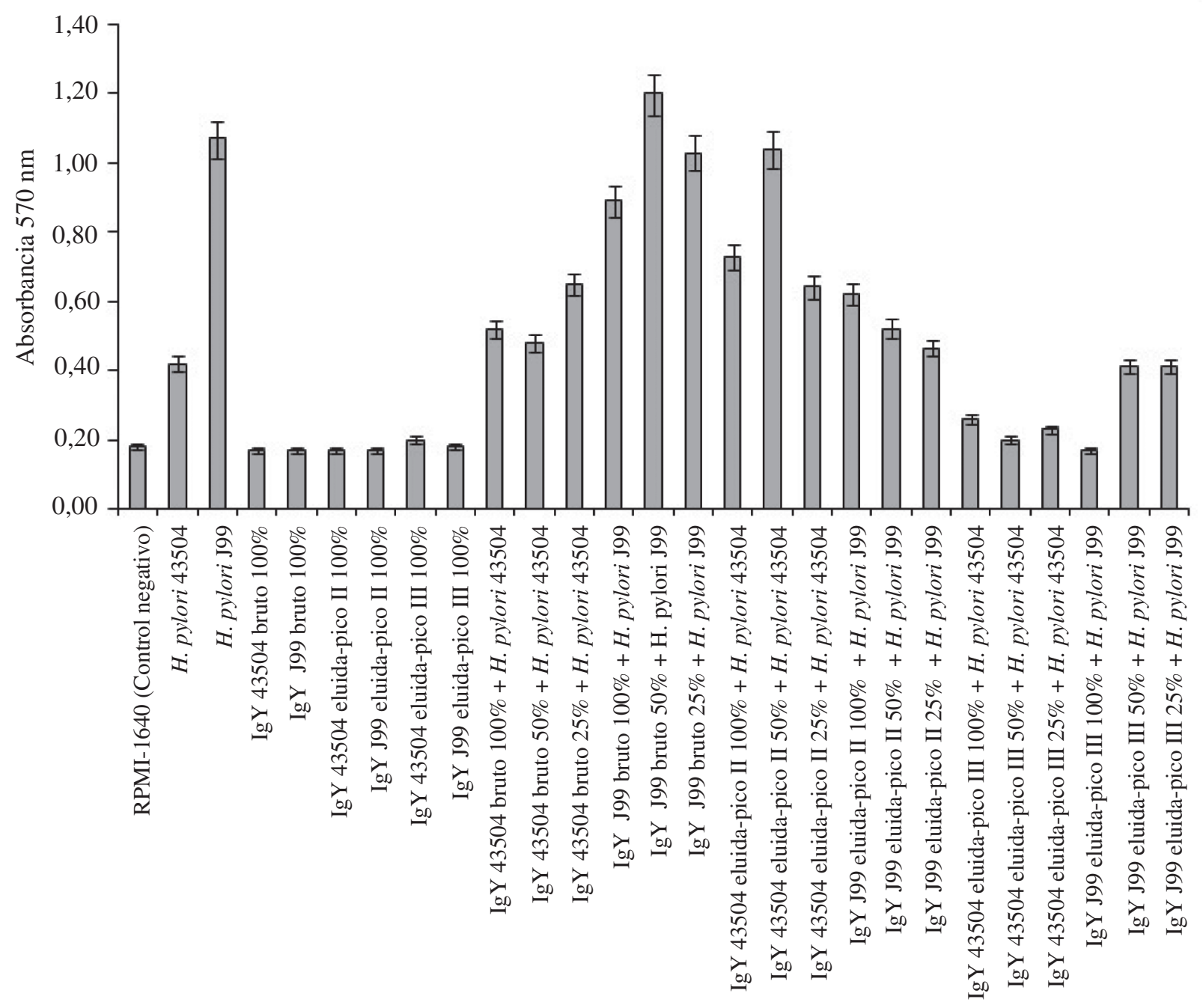

Muestras

Figura 5. Ensayo profiláctico para el desafío de la IgY anti-H. pylori contra las cepas J99 y 43504 en su forma no purificada (en bruto) y purificadas (eluida-pico II y eluida-pico III) en diferentes diluciones contra ambas cepas bacterianas de $H$. pylori en células AGS.

Prophylactic Assay for the challenge of avian IgY antibodies against H. pylori strains J99 and 43504 in their non-purified (crude) and purified (eluted-peak II and eluted-peak III) forms at different dilutions against both bacterial strains $H$. pylori in AGS cells.

huevo oscilaba entre 9,4-144 mg/mL. En el caso de nuestro estudio, al utilizar la técnica de precipitación con sulfato de amonio se obtuvo una concentración proteica de $\mathrm{IgY}$ que estuvo por debajo de lo esperado (menor a $5,4 \mathrm{mg} /$ $\mathrm{mL}$ ), lo que implicaría que nuestra técnica tuvo un bajo poder productivo, sumado al error humano en su ejecución.

Al respecto, la influencia que podría ejercer la especie de ave (Gongora y col 2008) con relación a la concentración de IgY en la yema de huevo no se contaría con información acerca de la concentración de $\operatorname{IgY}$ presente en gallinas araucanas (Gallus inauris). Sin embargo, Millet y col (2006) señalan que los pesos de las yemas de las gallinas araucanas $(15,80 \mathrm{~g})$ se encuentran entre los pesos de las yemas de las gallinas de las razas ISA Brown y Lohmann Selected Leghorn, es decir, entre 15,12 - 17,13 g. Además, estos autores establecen que la relación yema:albúmina es mayor en las gallinas araucanas $(0,60 \mathrm{~g})$ que las otras dos razas de gallinas ya mencionadas $(0,36 \mathrm{~g}$ en la gallina ISA Brown y $0,40 \mathrm{~g}$ en la gallina Lohmann Selected Leghorn). Por lo tanto, se podría obtener una mayor concentración de la IgY desde las yemas de los huevos de gallina araucana en relación con las otras razas o líneas genéticas aviares, situación que podría evaluarse en un segundo estudio comparativo.

A pesar de la baja concentración proteica de los anticuerpos purificados obtenida mediante la resina (Clontech) en la cromatografía de adsorción tiofílica, se obtuvieron anticuerpos de altísima pureza, particularmente la fracción eluida-pico III de ambas cepas, los que presentaron títulos mayores a los 1/6.400. Esto responde a la altísima 


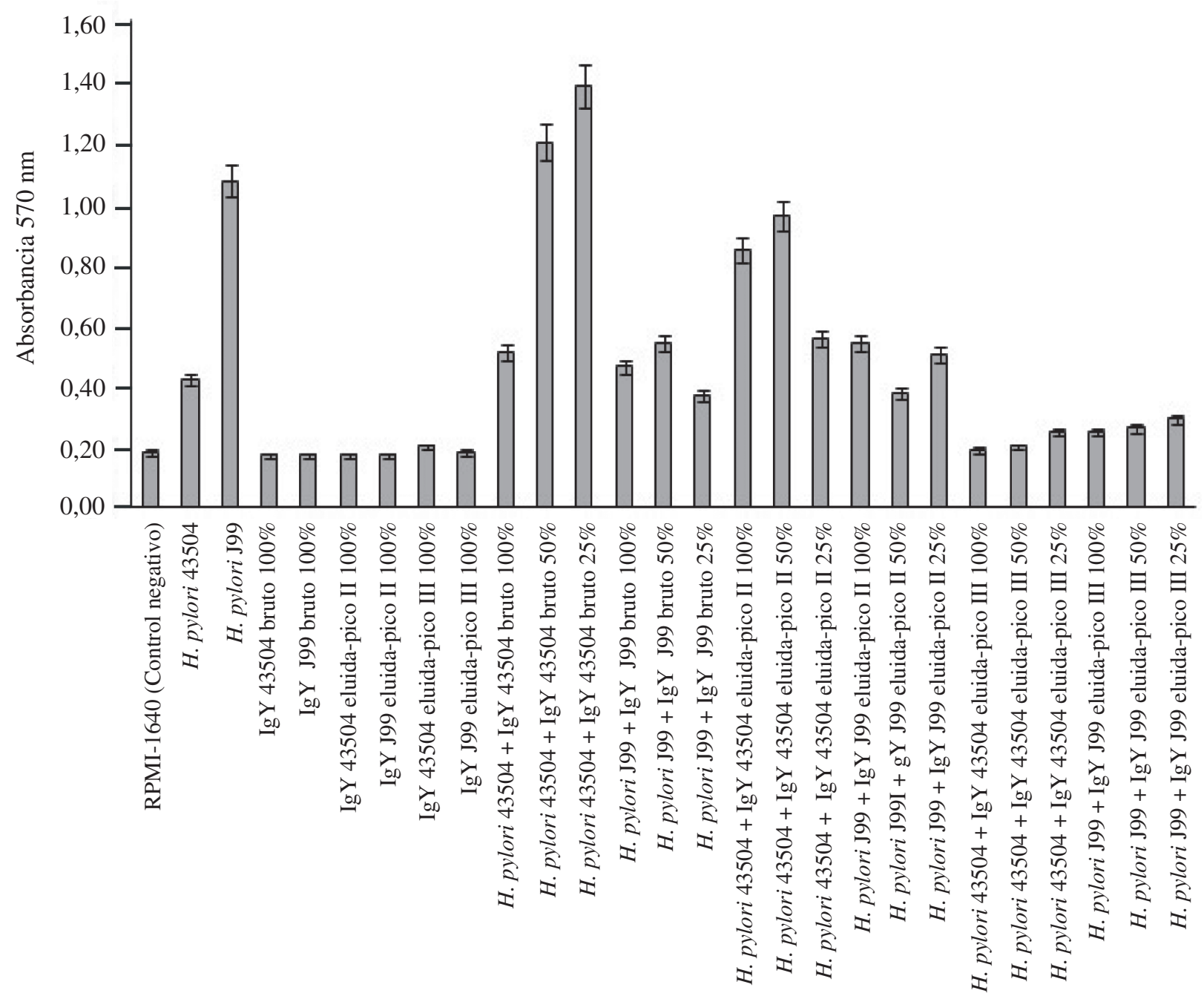

Muestras

Figura 6. Ensayo terapéutico para el desafío de la IgY anti-H. pylori contra las cepas J99 y 43504 en su forma no purificada (en bruto) y purificadas (eluida-pico II y eluida-pico III) en diferentes diluciones contra ambas cepas bacterianas de $H$. pylori en células AGS.

Therapeutic Assay for the challenge of avian IgY antibodies against H. pylori strains J99 and 43504 in their non-purified (crude) and purified (eluted-peak II and eluted-peak III) forms at different dilutions against both bacterial strains H. pylori in AGS cells.

sensibilidad que presentan ambos anticuerpos frente a los antígenos de H. pylori, especialmente en el caso de la IgY anti-H. pylori cepa J99. La razón de esto se debería a que esta cepa bacteriana produciría menor cantidad de arginasa en comparación con la cepa 43504, por lo que una baja producción de arginasa conduciría a una disminución de la urea endógena, con su consecuente reducción del amonio hidrolizado por la ureasa bacteriana, llevando así a una baja en la resistencia bacteriana al ácido (Hovey y col 2007), dando lugar a un mejor desempeño de la IgY anti-H. pylori cepa J99. Es factible notar que no se excluyen otros factores que pudiesen influir en un mejor desempeño de este anticuerpo aviar.

La elevada reacción cruzada de IgY anti $H$. pylori cepa J99 y 43504 contra los antígenos de ambas cepas de H. pylori se debió a que estos anticuerpos aviares reconocieron sus mismas proteínas inmunogénicas de las que se originaron. Sin embargo, también se observó una alta absorbancia en el ensayo de reacción cruzada para las bacterias $S$. aureus y E. coli. En el caso de $S$. aureus se postula que esta alta absorbancia se debería a la presencia de ciertos antígenos en común entre $H$. pylori y $S$. aureus. Esto se podría explicar por lo establecido por Cover y col (2003), quienes sugieren que podrían existir ciertas similitudes entre los mecanismos por los que VacA de $H$. pylori y la toxina $\alpha$ de S. aureus inducirían la apoptosis, las cascadas de señalización intracelulares específicas que se activarían por VacA en células epiteliales gástricas, situación aún por definirse. Ahora bien, la elevada absorbancia en el test de reacción cruzada de IgY anti-H. pylori con E. coli se debería también 
a la presencia de ciertos antígenos en común entre ambas especies bacterianas. De hecho, antiguamente se creía que pertenecían al mismo grupo filogenético, pero ahora se conoce que las especies de Helicobacter se ubican en una posición filogenéticamente diferente a las especies de Campylobacter, lo que le permitió la creación del género Helicobacter en 1989 (Goodwin y col 1989).

En los ensayos profilácticos y terapéuticos in vitro utilizando células AGS se observó que la IgY J99 eluida-pico III sin diluir (100\%) fue el que ejerció el mejor efecto protector en la mayoría de los ensayos, porque logró obtener la más baja absorbancia, es decir, logró una menor producción de urea de $H$. pylori. Por tanto, la fracción eluida-pico III de la IgY anti- $H$. pylori para ambas cepas bacterianas es un anticuerpo de altísima pureza, destacando el originado a partir de la cepa $H$. pylori cepa J99 en su fracción eluidapico III por su elevado poder inmunogénico alcanzado, el que podría incluso usarse a una dilución mucho mayor a 1/6.400. Por otra parte, sería recomendable incursionar en otros métodos de aislamiento de IgY desde la yema del huevo de gallina que sean más eficaces y de un mayor rendimiento productivo que el usado en este estudio.

Esta investigación abre las puertas para utilizar un método alternativo de obtención de anticuerpos a partir de la yema de huevos de gallinas que cumple con los principios de bienestar animal y su posterior uso en ensayos in vivo con el fin de controlar las infecciones causadas por agentes patógenos, en este caso, disminuir la alta prevalencia que tiene $H$. pylori a nivel mundial, especialmente en países subdesarrollados y en vías de desarrollo.

\section{REFERENCIAS}

Arachchi HSJ, V Kalra, B Lal, V Bhatia, CS Baba, S Chakravarthy, S Rohatgi, PM Sarma, V Mishra, B Das, V Ahuja. 2007. Prevalence of duodenal ulcer-gromoting Gene (dupA) of Helicobacter pylori in patients with duodenal ulcer in North Indian population. Helicobacter 12, 591-597.

Atherton JC, P Cao, RM Peek, MKR Tummuru, MJ Blaser, TL Cover. 1995. Mosaicism in vacuolating cytotoxin alleles of Helicobacter pylori. J Biol Chem 270, 17771-17777.

Björnham O, J Bugaytsova, T Borén, S Schedin. 2009. Dynamic force spectroscopy of the Helicobacter pylori BabA-Lewis b Binding. Biophysical Chemistry 143, 102-105.

Carlander D, A Larsson. 2001. Avian antibodies can eliminate interference due to complement activation in ELISA. Ups J Med Sci 106, 189-195.

Covacci A, S Censini, M Bugnoli, R Petracca, D Burroni, G Macchia, A Massone, E Papini, Z Xiang, N Figura, R Rappuoli. 1993. Molecular characterization of the $128-\mathrm{kDa}$ immunodominant antigen of Helicobacter pylori associated with cytotoxicity and duodenal ulcer. Proc Natl Acad Sci USA 90, 5791-5795.

Cover T, U Krishna, D Israel, R Peek. 2003. Induction of gastric epithelial cell apoptosis by Helicobacter pylori vacuolating cytotoxin. Cancer Res 63, 951-957.

Ferreccio C, A Rollán, PR Harris, C Serrano, A Gederlini, P Margozzini, C Gonzalez, X Aguilera, A Venegas, A Jara. 2007. Gastric cancer is related to early Helicobacter pylori infection in a high-prevalence country. Cancer Epidemiol Biomarkers Prev 16, 662-667.

Gongora J, NJ Rawlence, VA Mobegi, H Jianlin, JA Alcalde, JT Matus, O Hanotte, C Moran, JJ Austin, S Ulm, AJ Anderson, G Larson, A Cooper. 2008. Indo-european and asian origins for chilean and pacific chickens revealed by mtDNA. PNAS 105, 10308-10313.

Goodwin CS, JA Armstrong, T Chilvers, M Peters, D Collins, L Sly, W McConnell, W Harper. 1989. Transfer of Campylobacter pylori and Campylobacter mustelae to Helicobacter gen. nov. as Helicobacter pylori comb. nov. and Helicobacter mustelae comb. nov. respectively. Int J Syst Bacteriol 39, 397-405.

Hau J, C Hendriksen. 2005. Refinement of polyclonal antibody production by combining oral immunization of chickens with harvest of antibodies from the egg yolk. ILAR J 46, 294-299.

Hovey J, E Watson, M Langford, E Hildebrandt, S Bathala, J Bolland, D Spadafora, G Mendz, D McGee. 2007. Genetic microheterogeneity and phenotypic variation of Helicobacter pylori arginase in clinical isolates. BMC Microbiology 7, 1-15.

Kudo T, ZZ Nurgalieva, ME Conner, S Crawford, S Odenbreit, R Haas, DY Graham, Y Yamaoka. 2004. Correlation between Helicobacter pylori OipA protein expression and oipA gene switch status. J Clin Microbiol 42, 2279-2281.

Larsson A, A Karlsson-Parra, J Sjöquist. 1991. Use of chicken antibodies in enzyme immunoassays to avoid interference by rheumatoid factors. Clin Chem 37, 211-215.

Ledesma Z, B Gutiérrez, G Cirión, M Lemus, J Sanabría, T Romero, G Sierra, M Mirabal. 2010. Diagnóstico histológico de la infección por Helicobacter pylori en Pinar del Río, Cuba. VacciMonitor 19, 1-4.

Logan R, M Walker. 2001. Epidemiology and diagnosis of Helicobacter pylori infection. Br Med J 323, 920-922.

Marshall B, J Warren. 1984. Unidentified curved bacilli in the stomach of patients with gastritis and peptic ulceration. The Lancet 323, 1311-1315.

Martínez M, M González, R Ferreira, JA Mas Páez. 2008. Genotipo cag A+ en cepas de Helicobacter pylori asociadas a úlcera péptica, gastritis crónica y cáncer gástrico. Rev Cubana Med 47, 1-8.

Millet S, K de Ceuelaer, M Van paemel, K Raes, S de Smet, GPJ Janssens. 2006. Lipid profile in eggs of Araucana hens compared with Lohmann Selected Leghorn an ISA Brown hens given diets with different fat sources. Br Poult Sci 47, 294-300.

Mojca N. 2003. Production of antibodies in chickens. Food Technol Biotechnol 41, 259-267.

Ramírez A, R Sánchez. 2009. Helicobacter pylori 25 años después (1983 -2008): Epidemiología, Microbiología, Patogenia, Diagnóstico y Tratamiento. Rev Gastroenterol Perú 29, 158-170.

Rivas-Traverso F, F Hernández. 2000. Helicobacter pylori: Factores de virulencia, patología y diagnóstico. Rev Biomed 11, 187-205.

Shin J-H, M Yang, S Nam, J Kim, Na Myung, W-G Bang, I Roe. 2002. Use of egg yolk-derived immunoglobulin as an alternative to antibiotic treatment for control of Helicobacter pylori infection. Clin Diagn Lab Immunol 9, 1061-1066.

Suerbaum S, P Michetti. 2002. Helicobacter pylori infection. N Engl J Med 347, 1175-1186.

Sunwoo H, E Lee, K Menninen, M Suresh, J Sim. 2002. Growth inhibitory effect of chicken egg yolk antibody (IgY) on Escherichia coli O157:H7. J Food Sci 67, 1486-1494.

Tini M, UR Jewell, G Camenisch, D Chilov, M Gassmann. 2002. Generation and application of chicken egg-yolk antibodies. Comp Biochem Physiol A Mol Integr Physiol 31, 569-574.

Wilhelm O. 1953. La gallina araucana: estudios genéticos, $1^{\text {a }}$ comunicación. Bol Soc Biol Concep 28, 119-127. 